\title{
Can a Nordic diet be implemented as a new strategy for successful long-term weight loss maintenance in subjects with obesity?
}

\section{Abstract}

Introduction: A key problem in all weight-loss programs to fight obesity is the extent to which the body weight is maintained on a long-term basis. The study examines whether the 1-year consumption of healthy Nordic foods can result in better sustainable weight control compared to a control diet.

Material and methods: After a successful 6-week VLCD period in obese subjects ( $\mathrm{n}=80,52 \pm 10 \mathrm{y}, \mathrm{BMI} 34.4 \pm 3.1 \mathrm{~kg} / \mathrm{m}^{2}, 69 \%$ female; $93 \%$ completers, $-10.9 \pm 3.0 \mathrm{~kg}, \mathrm{p}<0.001$ ), the subjects were randomized to a new Nordic diet (NND) and a traditional Nordic diet (TND) group. The following 1-year period was a body weight maintenance period where the diets were implemented ad libitum. Weight, BMI, waist circumference and sagittal abdominal diameter were measured at 0 (immediately after VLCD), 6 and 12 months. Results are reported as mean \pm SEM. Differences in the anthropometric parameters between the diets at different time points compared to the start of the dietary intervention were statistically evaluated using a general linear model (GLM-ANOVA, Minitab Inc.).

Results: Forty-three subjects were randomized to NND and 37 to TND. In the NND group, 31 subjects completed the 6-month visit and 30 subjects 12-month visit. In the TND group, 24 and 21 completed 6-month and 12-month visit, respectively. We observed a non-significant difference in weight change at 6 months between NND $(0.04 \pm 0.87 \mathrm{~kg})$ and TND $(2.65 \pm 1.08 \mathrm{~kg})$. At $12 \mathrm{months}$, the weight change was significantly different between the diets (NND $1.94 \pm 0.99 \mathrm{~kg}$ and TND $5.69 \pm 1.41 \mathrm{~kg}, \mathrm{p}=0.029, \mathrm{R}^{2}=$ 9.39). Change in the BMI at 12 months was significantly lower for NND $(0.65 \pm 0.33 \mathrm{~kg} / \mathrm{m} 2)$ compared to TND (1.87 $\pm 0.46 \mathrm{~kg} /$ $\left.\mathrm{m}^{2}, \mathrm{p}=0.034, \mathrm{R}^{2}=8.87\right)$ but not at 6 months $\left(0.01 \pm 0.30 \mathrm{~kg} / \mathrm{m} 2\right.$ for NND and $0.84 \pm 0.36 \mathrm{~kg} / \mathrm{m}^{2}$ for TND). Differences in waist circumference (at 6 months $0.26 \pm 0.93 \mathrm{~cm}$ for NND and $3.30 \pm 1.45 \mathrm{~cm}$ for TND; at 12 months $1.04 \pm 1.01 \mathrm{~cm}$ for NND and $3.85 \pm$ $1.79 \mathrm{~cm}$ for TND) were not statistically different. The sagittal abdominal diameter was borderline statistically different at 6 months (NND $-0.28 \pm 0.29 \mathrm{~cm}$ and TND $\left.0.49 \pm 0.22 \mathrm{~cm}, \mathrm{p}=0.049, \mathrm{R}^{2}=7.09\right)$ but not at 12 months (NND $0.41 \pm 0.38 \mathrm{~cm}$ and TND $1.23 \pm+$ $0.42 \mathrm{~cm})$.

Conclusion: Results show a tendency that the type of diet has an impact on successful weight maintenance, with a benefit for the NND. Further statistical analyses including dietary compliance and biomarkers are needed and will be performed. Moreover, the study is ongoing with a total of 2-year follow-up.

\section{Conflict of Interest}

There is no conflict of interest. 